\title{
INDICATORS OF ENTERPRISE OPERATING ACTIVITIY AND LEVELS OF ITS ECONOMIC SECURITY
}

\begin{abstract}
Alina Ianioglo 1
Abstract: In the process of ensuring economic security of an enterprise, special attention should be paid to the economic security of production. This article describes the essence of indicators of operational activity: breakeven point, financial safety margin, and operating leverage. The analysis of these indicators shows that there are four levels of economic security of production. Formulas for determining these levels are presented and justified. The proposed method can be applied in practice and helps in determining the reserves for increasing efficiency of production.
\end{abstract}

JEL Classification: M11, D20, DOI: http://dx.doi.org/10.12955/cbup.v4.741

Keywords: economic security, break-even point, financial safety margin, operating leverage.

\section{Introduction}

At all stages of economic development enterprises are the main element of the economy. They represent an open dynamic system and operate under the influence of numerous factors, in conditions of environment instability. The statistics of world business shows that $80 \%$ of all newly established businesses cease during the first five years of their activity (Hindle, Klyver, 2011). Therefore, economic security of an enterprise is an important factor for improving its economic condition and ensuring its sustainable development.

The economic security of enterprises involves the most efficient use of resources and opportunities ensuring ongoing stable functioning and development. In determining the level of economic security of enterprise, special attention should be paid to indicators of operational activities. This study of the features of calculating break-even points, financial safety margins, and operating leverage becomes increasingly important as the analysis of these values can assist enterprises in making the right decisions.

The purpose of this article is to present a method of determining break-even points, financial safety margins, and operating leverage as indicators of the level of an enterprise's economic security.

\section{Methodology}

In order to achieve this article's purpose we have conducted analysis of scientific literature, enterprises data, and dependency between economic security of enterprise and indicators of operational activities such as: break-even point, financial safety margin, and operating leverage

\section{Results and discussion}

Gaponenko, Bespal'ko and Vlaskov (2007) considered economic security to be a condition of enterprise, which is characterized by its ability to properly function to achieve its goals and their change, within certain limits, under existing external conditions. In the process of ensuring the economic security of an enterprise, special attention should be paid to economic security in terms of its main activity (production activity). The study of the relationship between production volumes from one side, and cost of production and profit from another, will help an enterprise's management to make appropriate decisions. For this purpose, it is necessary to calculate the break-even points for determining the volume of production that ensures equality between sales revenue and total cost of production. Where actual production volume is below the break-even point, the production becomes unprofitable, but in case of the opposite, the enterprise will obtain a profit, and thus have the opportunity to develop (Parmacli, 2011). The break-even point $\left(\mathrm{q}_{\mathrm{min}}\right)$ can be determined by the equation:

\footnotetext{
${ }^{1}$ Alina Ianioglo, School of Economics and Business Administration, Tallinn University of Technology (Home university: Comrat State University, Moldova), alina.ianioglo@ gmail.com
} 


$$
q_{\min }=\frac{F C}{p-A V C}
$$

where: FC is the fixed cost;

p price per unit; and

AVC average variable cost per unit.

Thus, the cost structure should continuously consider the level of fixed cost as being significant for the enterprise's profit as each additional unit of production leads to yield increases, which cover fixed costs.

The analysis of the financial safety margin provides a more objective assessment of the economic security of an enterprise. The financial safety margin indicates the level of actual production in terms of its critical value. A relative indicator of financial safety margin (D) is calculated as follows (Parmacli, 2011):

$$
D=\frac{q-q_{\min }}{q} * 100 \%
$$

where: $\mathrm{q}$ is the actual level of the production volume.

This indicator shows the percentage of sales an enterprise can lose before it actually starts to lose money or stops making a profit. It indicates how far an enterprise is from a break-even point. A high financial safety margin ensures more opportunities to preserve profits in case of revenue decrease, and this positively affects the economic security of the enterprise.

Another indicator that reflects the condition of economic security of an enterprise is the operating leverage (L). This indicator represents the mechanism of control of the enterprise's profit, through the optimization of the ratio of fixed to variable costs (Parmacli, 2011):

$$
\mathrm{L}=\frac{\Delta P r}{\Delta N}
$$

where: $\Delta \mathrm{Pr}$ is growth of gross profit; and

$\Delta \mathrm{N}$ growth of revenue.

Formula of determining operating leverage may be also represented as follows (Parmacli, 2011):

$$
\mathrm{L}=1+\frac{F C}{P r}
$$

Operating leverage demonstrates the percentage point change in the enterprise profit from a change in revenue by one percentage point. Operating leverage characterizes the degree of an enterprise's business risk. The profits of an enterprise whose level of operating leverage is higher, are more sensitive to changes in sales revenues. An enterprise with a higher level of operating leverage is considered to be of higher risk. The enterprise's activity with low operating leverage is associated with lower risk, but also with smaller remuneration or net profit (Damodaran, 2012).

The analyzed indicators show the level of economic security of the main activity (production activity) of an enterprise. The graph of break-even points may indicate the level of economic security of production, as presented in Figure 1 using the example of production of cereal crops without corn at the enterprise "Ekinnik Yeri” SRL (2014), in the Republic of Moldova.

There are four different levels of production security: critical, low, medium, and high.

By analogy with the method of determining the level of economic security of production, based on the values of break-even point, we considered the indicators of financial safety margin (Figure 2).

The indicators of operating leverage in the production of cereal crops without corn at "Ekinnik Yeri" SRL (2014) are presented in Figure 3. 
Figure 1: Indicators of the break-even point by the example of production of cereal crops without corn at "Ekinnik Yeri" SRL, 2014)

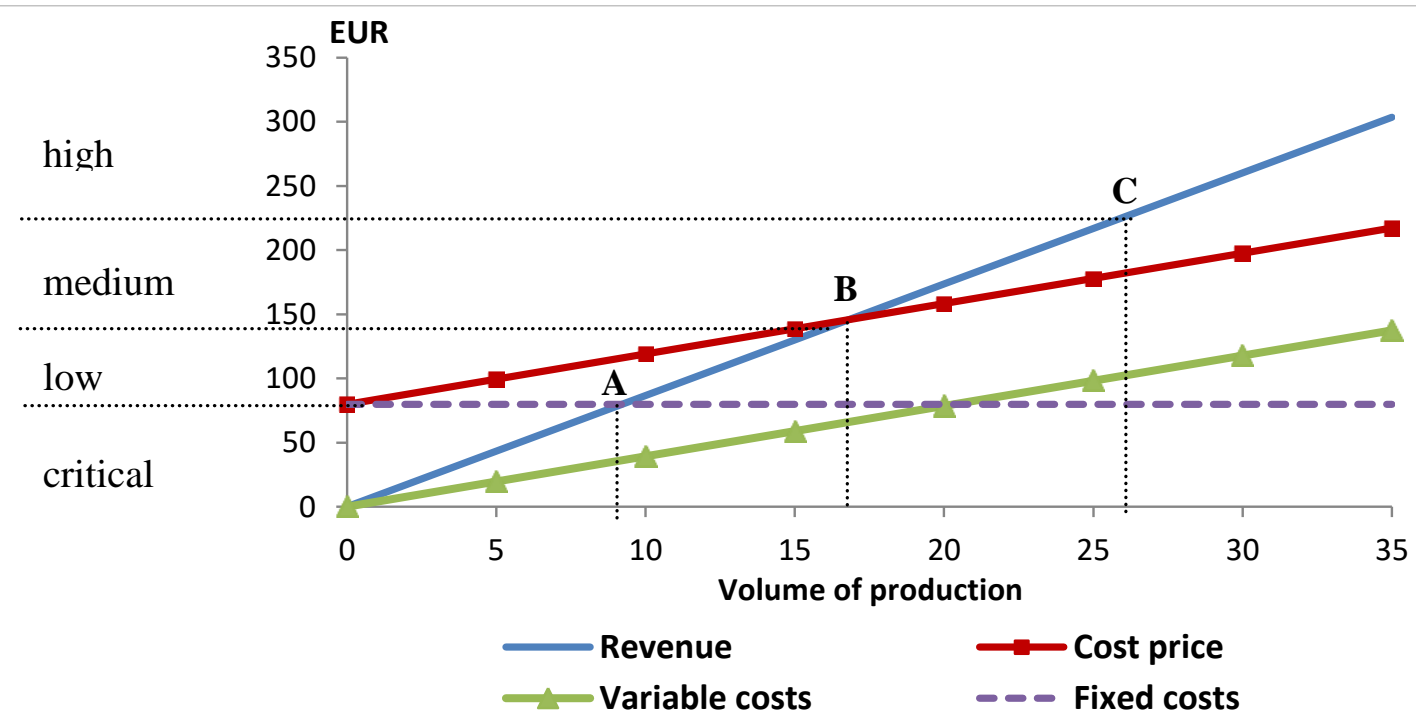

Source: Author

Figure 2: Indicators of financial safety margin point by the example of production of cereal crops without corn at "Ekinnik Yeri" SRL, 2014

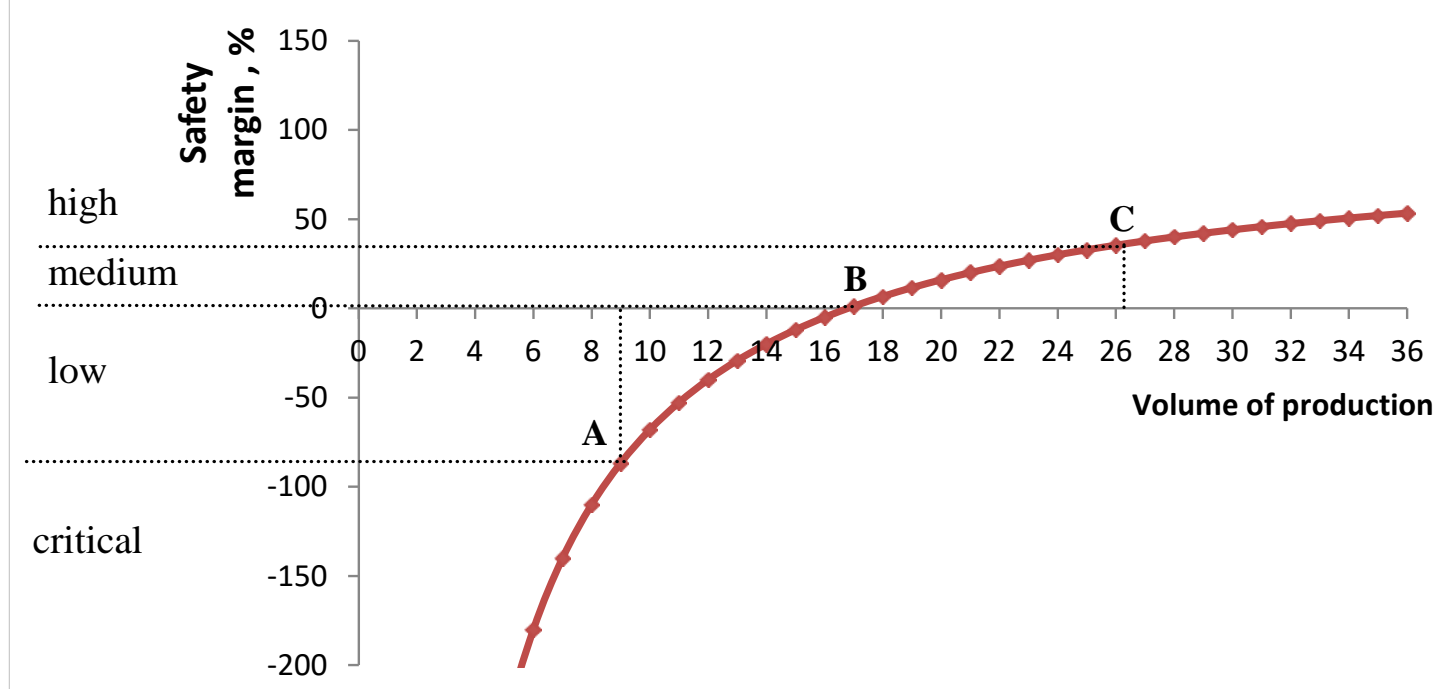

Source: Ianioglo and Parmacli (2015) 
Figure 3: Indicators of operating leverage point (by the example of production of cereal crops without corn at "Ekinnik Yeri" SRL, 2014)

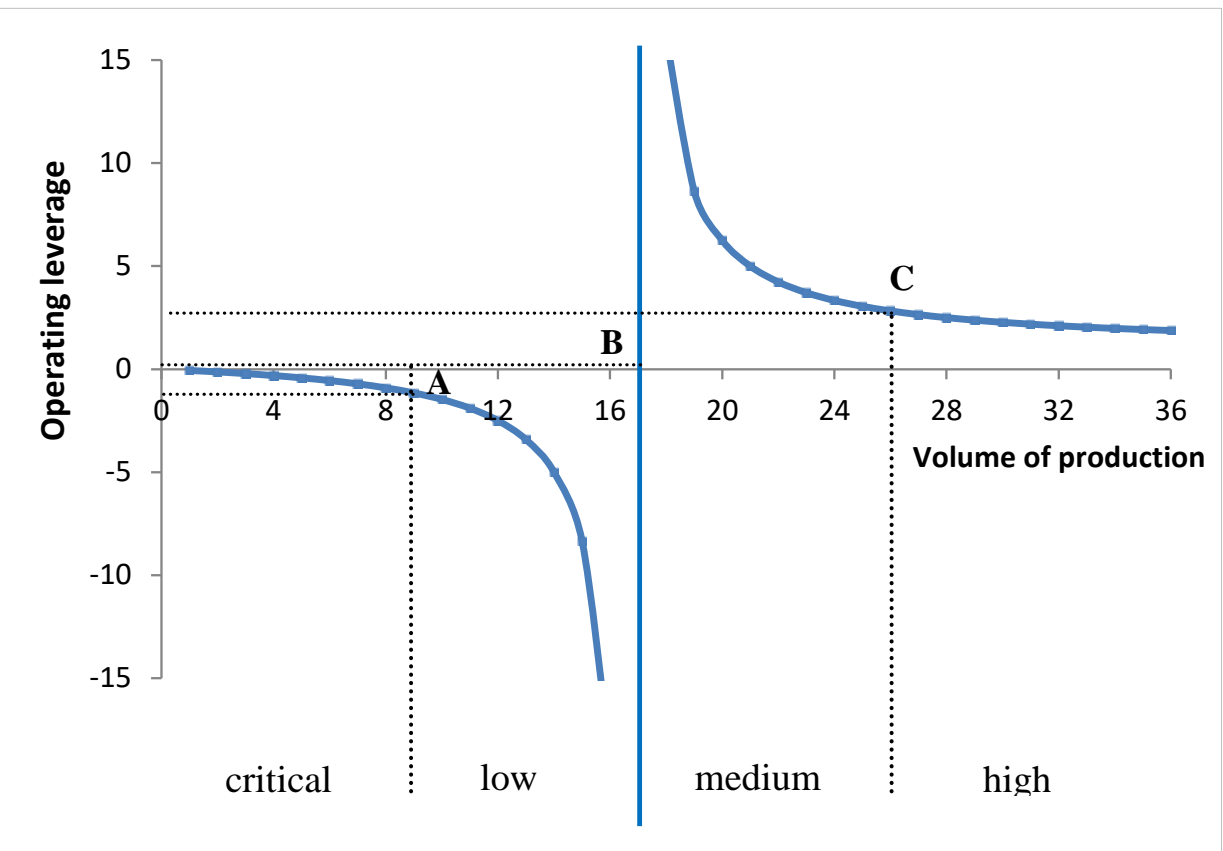

Source: Ianioglo and Parmacli (2015)

There are also four levels of economic security.

At the critical level, the revenue received from product sales do not cover total costs of the production. This level shows the riskiness of the business.

The enterprise is characterized by a low level of security when it reaches the intersection point of the curves of revenues and fixed costs (point "A"). The enterprise receives revenues from sales that cover fixed costs, while variable costs remain uncovered, and therefore the enterprise suffers losses. Point "A" on the graph can be determined by the following equation:

$$
N=F C
$$

where: $\mathrm{N}$ is the product sales revenue.

It follows from this that production volume at the point " $\mathrm{A}$ ", that is, the critical production volume $\left(\mathrm{q}_{\mathrm{cr}}\right)$, can be calculated as:

$$
\begin{aligned}
& q_{c r} * p=F C \\
& q_{c r}=\frac{F C}{p}
\end{aligned}
$$

Knowing the critical production volume, the level of financial safety margin can be calculated at the point " $\mathrm{A}$ " by the equation:

$$
\begin{gathered}
D=\frac{q-q_{\min }}{q} \\
D_{c r}=\frac{q_{c r}-q_{\min }}{q_{c r}}=\frac{\frac{F C}{p}-\frac{F C}{p-A V C}}{\frac{F C}{p}}=1-\frac{F C \cdot p}{F C \cdot(p-A V C)}=1-\frac{p}{p-A V C}=\frac{A V C}{A V C-p}=\frac{1}{1-\frac{p}{A V C}} \\
D_{c r}=\frac{1}{1-\frac{p}{A V C}}
\end{gathered}
$$

Based on Equations 4 and 5, it is proposed the operating leverage at the point "A" can be identified by: 


$$
\begin{aligned}
& L_{c r}=1+\frac{F C}{P_{r}}=1+\frac{F C}{N-F C-V C}=1+\frac{N}{N-N-V C}=1-\frac{p * q}{A V C * q}=1-\frac{p}{A V C} \\
& L_{c r}=1-\frac{p}{A V C}
\end{aligned}
$$

Point "B" on the graph represents the break-even point (Equation 1). The enterprise covers all its costs, but it still does not receive any profit. The value of the financial safety margin and operating leverage in the break-even point (point "B") is zero. After reaching the break-even point, the enterprise begins to profit with each subsequent unit of production. The range of the graph between points " $B$ " and " $C$ " represents the medium level of security. The higher the value of the financial safety margin, the more sustainable is the activity of the enterprise.

Once the break-even point is achieved, the profit grows faster than sales volume. The closer is the actual volume of production and sales in relation to their critical volumes, the smaller is the amount of profit and, therefore, the greater is the force of the operating leverage. Even a slight drop in sales can cause a substantial drop in profit.

Reaching point " $\mathrm{C}$ " ensures a high level of security for the enterprise. This is the level to which enterprises should strive. The enterprises need profit for further development, that is, to receive return on sales. Accordingly, we suggest to define point " $C$ " on the basis of return on sales (R):

$$
\begin{aligned}
& R=\frac{P r}{N} \\
& R=\frac{P r}{N}=\frac{q \cdot p-A V C \cdot q-F C}{q \cdot p}=1-\frac{A V C \cdot q+F C}{q \cdot p} \\
& q \cdot p \cdot(1-R)-A V C \cdot q=F C
\end{aligned}
$$

where: Pr is gross profit.

It follows that the equation for production volume can take the form as follows:

$$
q=\frac{F C}{q(1-R)-A V C}
$$

It is considered that the normative value of return on sales is 0.2. Thus, the volume of production and sales at the point " $C$ " can be determined by the equation:

$$
q_{o}=\frac{F C}{0.8 \cdot p-A V C}
$$

where: $\mathrm{q}_{\mathrm{o}}$ is the optimal volume of production.

The optimal volume of production represents the volume of products, which provides sales that allow enterprises to receive the necessary profit for further development, that is, to reach a return on sales.

Applying Equations 2 and 10, the financial safety margin at point " $\mathrm{C}$ " can be calculated as follows:

$$
\begin{aligned}
D & =\frac{q-q_{\min }}{q}=\frac{\frac{F C}{q \cdot(1-R)-A V C}-\frac{F C}{p-A V C}}{\frac{F C}{q \cdot(1-R)-A V C}}=\frac{F C \cdot p-F C \cdot p \cdot(1-R)}{(q \cdot(1-R)-A V C) \cdot(p-A V C)} \cdot \frac{q \cdot(1-R)-A V C}{F C}=\frac{p \cdot R}{p-A V C} \\
D & =\frac{R}{1-\frac{A V C}{p}}
\end{aligned}
$$

Applying Equations 4 and 10, the operating leverage at point "C" can be determined:

$$
\begin{aligned}
& L=1+\frac{F C}{P_{r}}=1+\frac{F C}{V-V C-F C}=1+\frac{F C}{p \cdot q-A V C \cdot q-F C}=1+\frac{F C}{\frac{p \cdot F C-A V C \cdot F C}{q \cdot(1-R)-A V C}-F C}=1+ \\
& \frac{F C \cdot p \cdot(1-R)-A V C}{F C \cdot(p-A V C-p(1-R)-A V C)}=1+\frac{p(1-R)-A V C}{p-p(1-R)}=\frac{p-p(1-R)+p(1-R)-A V C}{p-p(1-R)}=\frac{p-A V C}{p \cdot R} \\
& L=\frac{1-\frac{A V C}{p}}{R}
\end{aligned}
$$


Considering that the normative value of return on sales is 0.2 , the equations of the optimal financial safety margin $\left(\mathrm{D}_{\mathrm{O}}\right)$ and optimal operating leverage $\left(\mathrm{L}_{\mathrm{O}}\right)$ at point "C" take the form:

$$
\begin{aligned}
& D_{o}=\frac{0.2}{1-\frac{A V C}{p}} \\
& L_{o}=\frac{1-\frac{A V C}{p}}{0.2}
\end{aligned}
$$

The optimal values of the analyzed indicators demonstrated the condition of production and level of economic security of enterprise.

Proposed equations for calculating indicators of operational activities for determining the level of economic security are presented in Table 1.

Table 1: Formulas for calculating indicators of operational activities for determining the level of economic security in production

\begin{tabular}{|l|c|c|c|}
\hline \multicolumn{1}{|c|}{ Indicators } & Point A & Point B & Point C \\
\hline Production volume, $\mathbf{q}$ & $q_{\mathrm{\kappa p}}=\frac{F C}{p}$ & $q_{\min }=\frac{F C}{p-A V C}$ & $q_{o}=\frac{F C}{q\left(1-R_{v}\right)-A V C}$ \\
\hline $\begin{array}{l}\text { Financial safety } \\
\text { margin, D }\end{array}$ & $D_{\mathrm{\kappa p}}=\frac{1}{1-\frac{p}{A V C}}$ & 0 & $D_{o}=\frac{R_{p}}{1-\frac{A V C}{p}}$ \\
\hline Operating leverage, $\mathbf{L}$ & $L_{\mathrm{\kappa p}}=1-\frac{p}{A V C}$ & 0 & $L_{o}=\frac{p-A V C}{R_{p} \cdot p}$ \\
\hline Source: Author & & & \\
\hline
\end{tabular}

By using the presented equations and taking into account the current values of these indicators, the actual level of economic security of production can be identified.

\section{Conclusion}

We submit that the method suggested for analyzing the indicators of operational activities has a practical importance in assessing the level of economic security. The analysis identified four levels of economic security: critical, low, medium, and high. The critical level showed the riskiness of the business, with the high level indicating enterprises need profit for further development and economic security. One or all indicators may be applicable as they are interconnected and equally indicate the current level of security. Indicators of operational activities identify potential for improving technology and increasing the efficiency of production to maximize profits. This method allows one to identify the condition and determine directions of improving the economic security of an enterprise.

\section{References}

Damodaran A. (2012). Investment valuation: tools and techniques for determining the value of any asset. $3^{\text {rd }}$ ed. New Jersey: John Willey \& Sons [online]. [cited 22.02.2016]. Available from Internet: https://books.google.ee/

"Ekinnik Yeri" SRL, (2014). Forms 7-AIC and 9-AIC. Specialized forms of agricultural enterprise. National Bureau of Statistics of the Republic of Moldova.

Gaponenko,V. F., Bespal'ko, A. A., \& Vlaskov, A. S. (2007). Jekonomicheskaja bezopasnost' predprijatij. Podhodyi principy [Economic security of enterprise. Approaches and principles]. Moskva: Izdatel'stvo Os'-89.

Hindle, K., \& Klyver, K. (2011). Handbook of Research on New Venture Creation. Chelterham: Edward Elgar Publishing, Incorporated.

Ianioglo, A. I., \& Parmacli, D. M. (2015). Chapter 6. Effektivnost' zemlepol'zovaniya i ehkonomicheskaya bezopasnost' sel'skohozyajstvennyh predpriyatij. Parmacli, D.M.; Todorich, L.P.; Dudoglo,T.D.; Ianioglo, A.I. Jeffektivnost'

zemlepol'zovanija:Teorija, metodika, praktika [Land use efficiency: theory, methodology, practice]: Monografija. Gos.un-t, Nauch. issled. centr "Progress". Komrat: B. i.

Parmacli, D. M. (2011). Metodologiya nauchnyh issledovanij v ehkonomike [Methodology of scientific research in economy]. Comrat: Univ. de Stat. 